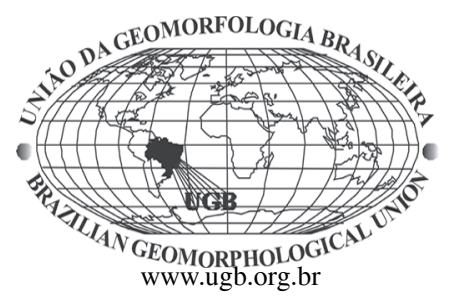

\title{
CARACTERIZAÇÃO HIDROLÓGICA E GEOMORFOLÓGICA DOS AFLUENTES DA BACIA DO RIO ARAGUAIA
}

\author{
Samia Aquino \\ Doutora em Ciências Ambientais - University of Texas at Austin - Department of Geography and Environment - GRG 334 \\ - A3100 - Austin - TX - 78712 - USA - e-mail: samia_aquino@yahoo.com.br
}

Edgardo M. Latrubesse

Doutor em Ciências Geológicas - University of Texas at Austin - Department of Geography and Environment GRG 334 - A3100. Austin - TX - 78712,USA - e-mail: latrubesse@igs.edu.ar

Edvard Elias de Souza Filho

Doutor em Geologia, Professor - Universidade Estadual de Maringá - e-mail: edvardmarilia@wnet.com.br

\begin{abstract}
Resumo
O conhecimento do comportamento hidrológico e geomorfológico da bacia do Araguaia têm avançado significativamente nos últimos anos. Porém, dados essenciais para o entendimento do sistema e para o planejamento de recursos hídricos, como são as estimativas de aportes líquidos anuais dos tributários não foram obtidos. Neste artigo se organizou uma regionalização baseada na geologia e geomorfologia dominantes das bacias dos afuentes, se caracterizou o funcionamento hidrológico geral dos mesmos e com as 11 estações dos tributários disponíveis para toda a bacia se calculou uma curva de correlação entre as variáveis área de drenagem e vazão. Devido à falta de estações fluviométricas no baixo curso dos afluentes, se estimaram os aportes líquidos médios anuais dos mesmos por meio da utilização de área de drenagem na foz dos tributários. Foram calculados posteriormente, os aportes correspondentes para a alta, média e baixa bacia. Estes valores estimados da curva foram confrontados com os dados existentes nas principais estações hidrológicas localizadas no canal principal do Araguaia ( 9 estações).

O Alto curso tem uma representatividade de 10,4\% do fluxo da bacia. O médio Araguaia contribui com 77,5\% da descarga total e o baixo Araguaia contribui com $12,06 \%$ da vazão da bacia. A respeito da entrada por margens, os afluentes da margem esquerda contribuem com 179.363,88 $\mathrm{km}^{2}$ e uma vazÃo média anual de $2.785,13 \mathrm{~m}^{3} / \mathrm{s}$ enquanto os da margem direita aportam $3.223,28 \mathrm{~m}^{3} / \mathrm{s}$ de vazão média anual drenando uma totalidade de $204.635,56 \mathrm{~km}^{2}$.
\end{abstract}

Palavras-chave: Rio Araguaia, tributários, hidrologia, vazão, áreas de drenagem.

\begin{abstract}
The knowledge of the hydrologic and geomorphologic behavior of the Araguaia fluvial system advanced significantly during the last years. However, some essential data such as the mean water annual discharge sourced by the tributaries to the Araguaia main stem are yet unknown.

In this paper the tributaries were classified in function of the basin geology and geomorphology and hydrologic regime. Processing data from 11 gauge stations available from the tributaries, a probabilistic curve drainage area vs. mean annual discharge was obtained. By using the equation and the drainage area to the tributaries mouth, the mean annual discharge was calculated for each tributary. The data (balance of tributary inputs in relation to the main stem record) were checked comparing the data estimated from the curve with the data from 9 gauge stations along the Araguaia River.

The upper basin represents $10.4 \%$ of the water discharge. The middle basin contributes with $777.54 \%$ of water discharge and the lower Araguaia with $12.06 \%$ of the water discharge. The tributaries from the right bank contribute with $179.363,88 \mathrm{~km}^{2}$ of drainage area and a mean annual discharge of $2,785.13 \mathrm{~m}^{3} / \mathrm{s}$. The tributaries from the left bank contribute with a mean annual discharge of $3,223.28 \mathrm{~m}^{3} / \mathrm{s}$ draining $204.635,56 \mathrm{~km}^{2}$.
\end{abstract}

Keywords: Araguaia River, tributaries, hydrology, discharge, drainage area 


\section{Introdução}

A utilização dos recursos hídricos no Brasil foi intensificada com o desenvolvimento do país, tanto no que se refere ao aumento da quantidade exigida para determinado emprego, quanto ao que está relacionado a variedade dessas utilizações que incluem o abastecimento público, consumo industrial, irrigação, recreação, geração de energia e transporte.

No caso do Brasil Central, até a década de 50, o Cerrado brasileiro manteve-se quase inalterado por ação antrópica. A partir dos anos 60, esse ecossistema foi sendo perturbado, dando margem à pecuária e à agricultura extensiva. Essas mudanças se apoiaram sobretudo na implantação de novas infra-estruturas viárias e energéticas. Os desmatamentos, queimadas, uso de fertilizantes químicos e agrotóxicos, resultaram em $64 \%$ de áreas do Cerrado altamente modificadas (AGMA et al., 2004), o que tem produzido resposta variadas dos sistemas fluviais aos processos de erosão e sedimentação com presença de voçorocas e assoreamento de alguns canais.

A partir da década de 90, governos e vários setores organizados da sociedade debatem como conservar o restante do Cerrado, com o intuito de buscar tecnologias embasadas no uso adequado dos recursos hídricos, no ecoturismo e em outras iniciativas que possibilitem um modelo de desenvolvimento sustentável, com perspectivas de preservação e proteção (Arruda et al., 2000). Porém, o Cerrado, encontra-se, até o momento, pouco valorizado em termos de conservação, apresentando apenas $1,7 \%$ de sua área assegurada na forma de parques ou reservas naturais (Brasil, 2003). Dentro deste marco, a bacia do rio Araguaia é considerada como uma das áreas prioritárias para a conservação da biodiversidade aquática do cerrado (Arruda et al., 2000).

Pesquisas que abordam diferentes focos de análises sobre a bacia do Araguaia, particularmente no médio curso, aumentaram desde finais dos anos 90. No entanto, embora já existam trabalhos sobre a dinâmica hidrológica do rio Araguaia, e importantes avanços no conhecimento de certos aspectos morfométricos, limnológicos e sedimentométricos, o funcionamento hidrológico dos tributários é ignorado, e não se conhece realmente qual é o aporte dos afluentes para a bacia, devido principalmente à falta de estações fluviométricas disponíveis. Basicamente, se desconhecem dados fundamentais dos afluentes como, por exemplo, aporte médio anual de cada bacia, e uma descrição geral das suas características hidrológicas e geomorfológicas.

Partindo dessa afirmativa, no que diz respeito a grande parte das sub-bacias do Araguaia, este artigo se propõe complementar e adicionar informações às pesquisas já existentes, tendo como objetivos organizar os dados fluviométricos sobre cada afluente, caracterizar as sub-bacias de acordo com as distintas unidades geomorfológicas presentes na bacia do
Araguaia, realizar uma caracterização básica do comportamento hidrológico e estimar o aporte médio anual de vazão dos afluentes ao sistema fluvial do Araguaia.

\section{O Rio Araguaia e seus Afluentes}

A bacia hidrográfica do Tocantins-Araguaia é considerada a quarta maior bacia de drenagem da América do Sul, estende-se por $777.308 \mathrm{~km}^{2}$, abrangendo extensões de dois grandes biomas sul-americanos: a floresta tropical amazônica ao Norte e a vegetação de Cerrado ao Sul.

O rio Araguaia é o principal sistema da bacia AraguaiaTocantins tanto no que se refere a área de drenagem como a vazão. Possui uma área aproximada de 383.999 km² (Souza, 2002), distribuída em quatro Estados: Goiás, Mato Grosso, Pará e Tocantins, embora grande parte da bacia situa-se na região Centro-Oeste.

O Araguaia transcorre aproximadamente $2.100 \mathrm{~km}$ até a confluência com o rio Tocantins. Após percorrer 570 km (médio curso), divide-se em dois braços: O Araguaia e o Javaés, formando o que alguns consideram como a maior ilha fluvial do mundo, a Ilha do Bananal.

Segundo Latrubesse e Stevaux (2002), o rio Araguaia é dividido em três segmentos: alto, médio e baixo Araguaia (Figura 1). $\mathrm{O}$ alto Araguaia drena uma área de $36.400 \mathrm{~km}^{2} \mathrm{e}$ se desenvolve da cabeceira até a cidade de Registro do Araguaia. Nesse setor o rio corre encaixado sobre embasamento cristalino composto por rochas pré-cambrianas e sedimentos paleozóicos da Bacia do Paraná (Figura 2).

Os principais afluentes desse setor são os rios: das Garças e Diamantino que fluem essencialmente pela margem esquerda (Figura 1).

No médio curso que se estende por $1.160 \mathrm{~km}$ desde Registro do Araguaia até Conceição do Araguaia, a área de drenagem aumenta drasticamente, alcançando uma área maior que $300.000 \mathrm{~km}^{2}$.

Nesse trecho, o rio flui através de uma planície aluvial bem desenvolvida considerada um complexo mosaico de unidades morfo-sedimentares formadas por sedimentos do Holoceno e do Pleistoceno tardio.

Neste setor encontram-se os principais afluentes da bacia Araguaia, constituído pela margem direita pelos rios: Caiapó, Claro, Vermelho, Tesouras, do Peixe, Crixás-Açu, Formoso, Côco, Caiapó II, Piranhas e pela margem esquerda, os rios: Cristalino, Tapirapê e das Mortes (Figura 1).

O rio das Mortes que nasce na Serra do Roncador é considerado o mais importante tributário do canal principal, com aproximadamente $60.000 \mathrm{~km}^{2}$ de área de drenagem, flui através da margem esquerda, apresenta padrão sinuoso e transcorre ao longo da Planície do Bananal em direção paralela com o rio Araguaia. 


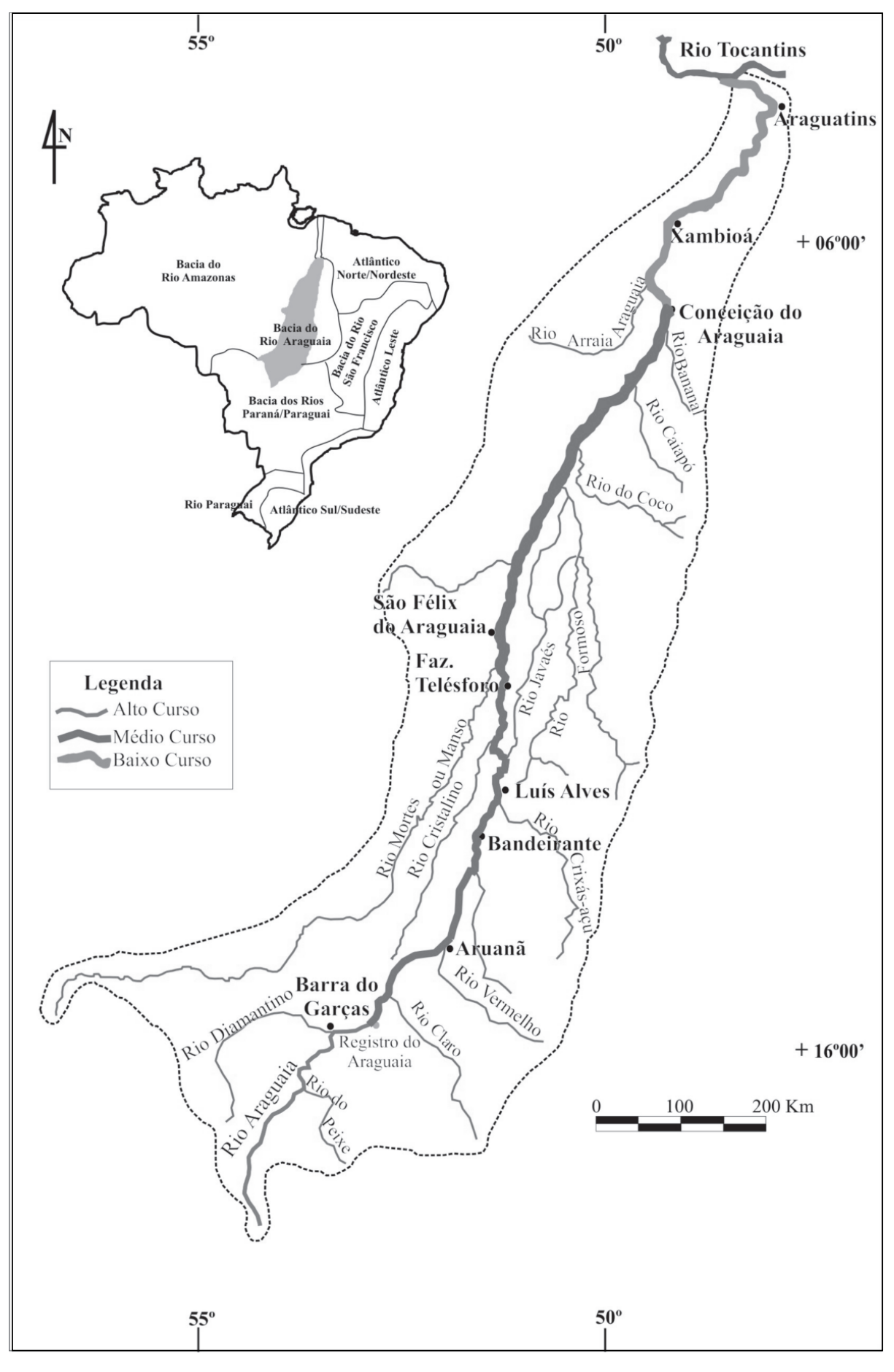

Fonte: LABOGEF

Figura 1 - Bacia do rio Araguaia e principais estações fluviométricas

O baixo Araguaia se constitui depois da localidade de Conceição do Araguaia até sua confluência com o rio Tocantins. Inicia-se depois da planície do Bananal, quando a planície aluvial praticamente desaparece e o rio entra em área de rochas paleozóicas e principalmente, de rochas cristalinas pré-cambrianas, com extensão aproxi- mada de $500 \mathrm{~km}$ até a confluência com o Tocantins (Figura 2). Os principais afluentes desse trecho são pela margem direita os rios: Jenipapo, Muricizal, Lontra, Corda, Piranhas II, Martinho e Barreiro, e pela margem esquerda os rios: Pau'darco, Itaipava, Xambioá e Gameleira. 


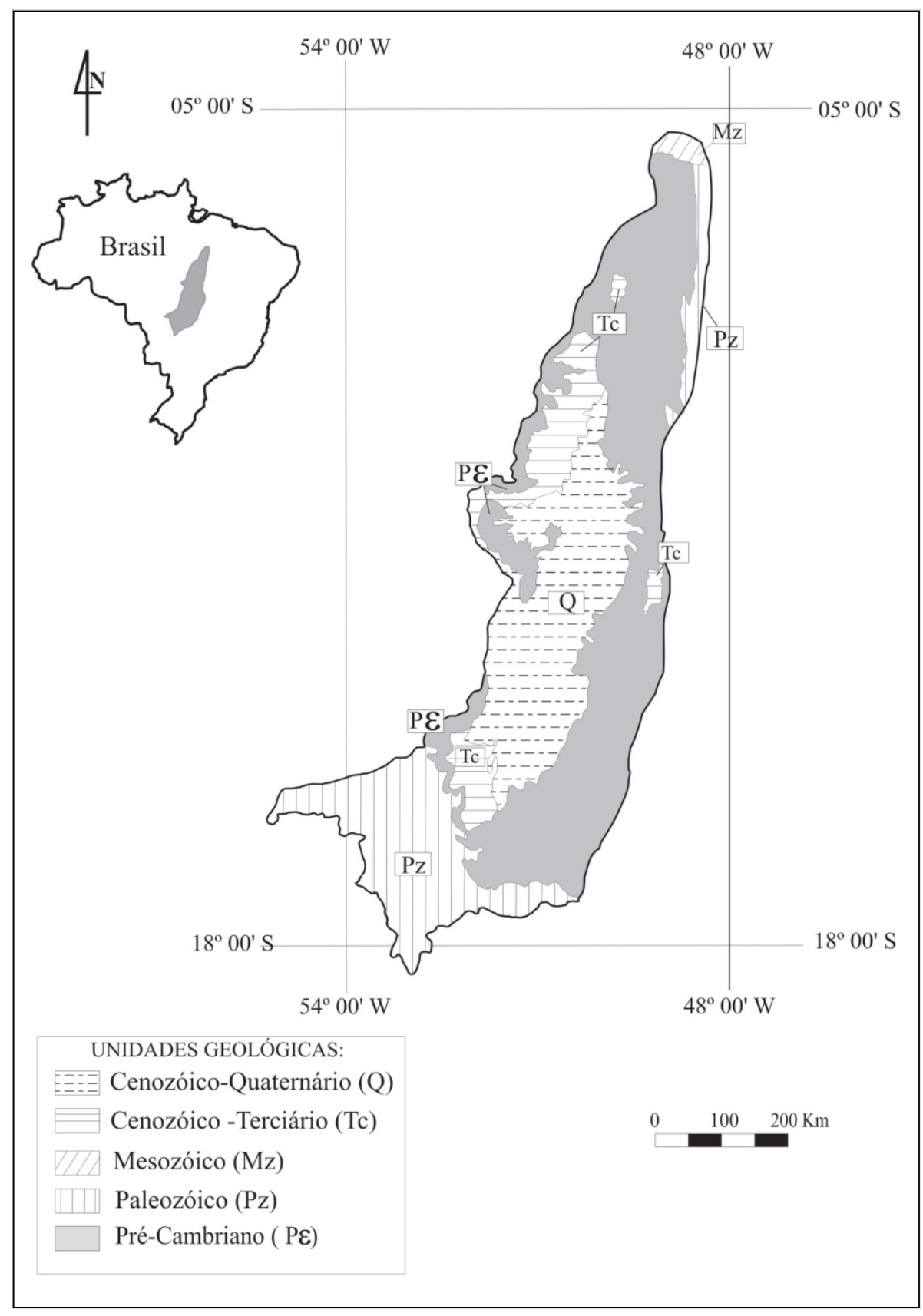

Fonte: LABOGEF

Figura 2 - Unidades Geológicas da Bacia do Rio Araguaia

\section{Aspectos Climáticos da Bacia}

As condições climáticas que predominam na bacia são de natureza continental tropical, devido à sua posição continental, não sofre o efeito direto da confluência intertropical. Apresentase semi-úmido com tendência a úmido, com a 4 a 5 meses secos.

O clima é marcado por uma estação chuvosa e uma seca, com um mês de transição entre elas. O período mais chuvoso estende-se de outubro a abril, e o mais seco está compreendido entre maio e setembro. Na parte norte da bacia os meses de janeiro a março são os mais chuvosos, e nas partes central e sul a pluviosidade é maior entre dezembro e fevereiro (SGM, 2006).

\section{Regionalização Geológica/Geomorfológica dos Afluentes da Bacia}

Grandes rios tropicais fluem sobre uma multiplicidade de províncias geológica-geomorfólogicas constituídas por cinturões 
orogenéticos, platôs/plataformas sedimentares e basálticas, áreas cratônicas, planícies em bacias sedimentares e áreas geologicamente variadas (mistas), sendo que a bacia do rio Araguaia drena principalmente sobre terrenos mistos dominados por plataformas constituídas por bacias sedimentares paleozóicasmesozóicas e áreas cratônicas, bastante estáveis do embasamento cristalino pré-cambriano (Latrubesse et al., 2005).

A bacia do rio Araguaia é dominada por 3 unidades geológicas principais constituídas por rochas pré-cambrianas, rochas paleozóicas e mesozóicas da bacia do Paraná e sedimentos terciários e depósitos quaternários na planície do Bananal (Latrubesse e Stevaux, 2002; Valente, 2007) (Figura 2).

\section{Rios da alta bacia que drenam dominantemente rochas Paleozóicas e Mesozóicas da Bacia do Paraná}

Esta unidade geológica é formada basicamente por arenitos, siltitos, argilitos e basaltos da Província Geológica do Paraná, onde escoam rios menores da alta bacia como o Diamantino e das Garças. O rio das Mortes nasce nessa unidade, mas logo transcorre sobre sedimentos Cenozóicos Terciário e Quaternário (Tabela 1).

Tabela 1 - Tributários do rio Araguaia e respectivas unidades geomorfológicas as quais drenam.

\begin{tabular}{|c|c|c|}
\hline \multirow{4}{*}{ Alto Araguaia } & \multirow{4}{*}{$\begin{array}{c}\text { Rios que drenam } \\
\text { dominantemente sobre } \\
\text { rochas Paleozóicas - } \\
\text { Mesozóicas da Bacia do } \\
\text { Paraná }\end{array}$} & Diamantino \\
\hline & & Garças \\
\hline & & Peixes I \\
\hline & & Peq. Afluentes \\
\hline \multirow{15}{*}{ Médio Araguaia } & \multirow{11}{*}{$\begin{array}{c}\text { Rios que drenam } \\
\text { dominantemente sobre } \\
\text { rochas Pré-Cambrianas }\end{array}$} & Caiapó \\
\hline & & Claro \\
\hline & & Vermelho \\
\hline & & Peixes \\
\hline & & Crixás-Açu \\
\hline & & Formoso \\
\hline & & $\begin{array}{l}\text { Vários afluentes da margem } \\
\text { direita do rio Javaés }\end{array}$ \\
\hline & & Côco \\
\hline & & Caiapó II \\
\hline & & Piranhas \\
\hline & & Sub bacias 12,13 e 14 \\
\hline & \multirow{4}{*}{$\begin{array}{c}\text { Rios que drenam } \\
\text { dominantemente sobre } \\
\text { Planície de sedimentos } \\
\text { do Cenozóico tardio }\end{array}$} & $\begin{array}{l}\text { Mortes (nasce na unid. } \\
\text { Paleozóica- Mesozóica) }\end{array}$ \\
\hline & & Cristalino \\
\hline & & Tapirapê \\
\hline & & $\begin{array}{l}\text { Sub bacias V, VI, VII, VIII, } \\
\text { IX, X, XI (nascem na unid. } \\
\text { Pré-cambriana) XII, XIII, } \\
\text { XIV e XV }\end{array}$ \\
\hline \multirow{17}{*}{ Baixo Araguaia } & \multirow{17}{*}{$\begin{array}{c}\text { Rios que drenam } \\
\text { dominantemente sobre } \\
\text { rochas Pré-Cambrianas }\end{array}$} & Sub 15 \\
\hline & & Cunhas \\
\hline & & Jenipapo \\
\hline & & Muricizal \\
\hline & & Sub 18 \\
\hline & & Lontra \\
\hline & & Corda \\
\hline & & Piranha III \\
\hline & & Martinho \\
\hline & & Barreiro \\
\hline & & Sub XVI \\
\hline & & Pau d'arco \\
\hline & & $\begin{array}{l}\text { Rib.Andorinhas e } \\
\text { peq.Córregos }\end{array}$ \\
\hline & & Rib. Água Fria \\
\hline & & Sub XX \\
\hline & & Itaipava \\
\hline & & $\begin{array}{l}\text { Xambioá, Gameleiras e } \\
\text { Córregos }\end{array}$ \\
\hline
\end{tabular}

Os principais sistemas fluviais do alto Araguaia têm suas cabeceiras associadas e circulam entalhados na superfície regional de aplanamento III e em parte na superfície IVc. Nesta unidade se encontra associada a essa rede de drenagem uma série de espetaculares voçorocas (Marinho et al., 2006).

\section{Rios que drenam dominantemente ao longo de Planícies sedimentares Quaternárias}

O médio curso da bacia Araguaia recebe uma série de afluentes que transcorrem, do ponto de vista geomorfológico, sobre uma planície fluvial ligeiramente dissecada, comumente conhecida como planície do Bananal, a qual se estende desde Caseara, ao norte, até Registro do Araguaia, ao Sul, ao longo de aproximadamente 730 $\mathrm{km}$. Esta unidade geomorfológica está formada principalmente por sedimentos aluviais Terciários e Quaternários da Formação Araguaia, as vezes cobertos com crostas lateríticas.

O mais importante tributário do Araguaia é o rio das Mortes, que apesar de possuir suas cabeceiras formadas nos relevos tabuliformes da Bacia do Paraná é sustentado na margem esquerda pelas terras altas da Serra do Roncador e na margem direita pela planície do Araguaia.

Dentro dessa categoria também se encontra o Javaés, o qual se trata de um rio sub-adaptado (under-fit stream) que circula ocupando uma antiga faixa fluvial abandonada do rio Araguaia. Devido ao fato de não possuir cabeceira sua dinâmica hidrológica é totalmente dependente do regime hidrológico do rio Araguaia, que o alimenta durante o período de cheias.

O terceiro rio em importância desse sistema é o Cristalino, que nasce dentro da planície do Bananal, ocupando um sistema de antigos paleocanais sobre a planície do Bananal.

Os rios alimentados pelas terras baixas da planície constituem as bacias dos rios Cristalino, Tapirapê e alguns afluentes da margem esquerda do rio Javaés, e outras pequenas bacias do médio curso que têm suas cabeceiras originadas no escudo, mas transcorrem quase integralmente através da planície (Tabela 1).

\section{Rios que drenam rochas do Embasamento Cristalino Pré- cambriano}

Em grande parte da bacia Araguaia os afluentes, principalmente os de margem direita do alto, médio e baixo cursos e os de margem esquerda do baixo curso, nascem e transcorrem sobre uma variedade de rochas pré-cambrianas formadas por quartizitos, migmatitos, granulitos, gnaisse e xistos, dominantemente, das províncias geológicas do Tocantins, da Amazônia Central e Carajás (Tabela 1). 
Do ponto de vista geomorfológico, possuem as cabeceiras numa série de Colinas e morros, fundamentalmente com controle estrutural ou superfícies regionais de aplanamento, que se estendem de norte a sul no centro do Estado de Goiás.

Dentro desse grupo se encontram os principais afluentes da margem direita no médio Araguaia, os quais drenam integralmente dentro do Estado de Goiás, sendo eles: os rios Peixes, Claro, Vermelho e Crixás-Açu, esses rios apresentam planícies bem desenvolvidas e complexa, com padrão dominantemente meandriforme, dentro dessa planície se identificam meandros abandonados e espiras de meandros, o conjunto desses sistemas representam as maiores áreas de sedimentação fluvial do Estado de Goiás.

No baixo Araguaia também afloram rochas paleozóicas e mesozóicas da Província Geológica Paranaíba, embora não são arealmente dominantes.

Do ponto de vista da unidade geológica/geomorfológica os rios de planície representam uma área de 119.774 km², ou seja, $31,2 \%$ da área total da bacia, enquanto os rios que drenam através das unidades Pré-Cambriana constituem 225.536 $\mathrm{km}^{2}$, o que representa $58,8 \%$ da bacia, e os rios que drenam sobre a Província geológica do Paraná correspondem a 38.688 $\mathrm{km}^{2}$ e $10 \%$ da bacia.

\section{Regime Hidrológico na Bacia Araguaia}

\section{Distribuição das vazões no canal principal}

Dados de vazão média anual, picos máximos e mínimos, picos máximos da série histórica, em ordem de magnitude, são mostrados para as nove estações do rio Araguaia na tabela 2 .

Os picos de cheias do Araguaia acontecem nos meses de janeiro a maio, contudo no alto curso em alguns anos há variabilidades e acréscimos nos picos que começam no mês de dezembro. Os maiores picos geralmente acontecem entre janeiro e março para o alto e médio curso, já para o baixo curso se dão a partir de março a abril, se constituindo num regime relativamente simples com uma temporada de cheia e outra de seca que está em conformidade com o clima da bacia.

O rio Araguaia tem picos de vazão bem definidos durante a estação chuvosa e fluxos bem inferiores durante a estação seca, quando diminui as chuvas. A grande variabilidade estacional é refletida em todos os setores do curso prin- cipal caracterizando a grande variabilidade de descargas em sistemas fluviais tropicais (Tabela 2).

Geralmente, no alto curso (Barra do Garças) e no início do médio curso (Aruanã), onde o rio flui sobre rochas da bacia sedimentar do Paraná e Pré-cambrianas, ocorrem vazões com valores entre 9 e 7 vezes maiores que a média da série, já no médio curso, no qual o rio transcorre principalmente sobre sedimentos da planície aluvial, os valores estão entre 3 e 4 da média, e novamente tornam a se elevar no baixo curso, com valores que estão entre 4 e 6 (Figura 3).

Tabela 2 - Dados hidrológicos com coeficientes médios de variabilidade de vazões para o rio Araguaia.

\begin{tabular}{|c|c|c|c|c|c|c|}
\hline $\begin{array}{l}\text { Estação } \\
\text { Hidrológica }\end{array}$ & $\begin{array}{c}\text { Área de } \\
\text { Drenage } \\
\mathrm{m} \mathrm{km}^{2}\end{array}$ & $\begin{array}{c}\text { Vazão Média } \\
\text { Anual } \\
\operatorname{Qm}\left(\mathrm{m}^{3} / \mathrm{s}\right)\end{array}$ & $\begin{array}{c}\text { Vazão } \\
\text { Máxima } \\
\text { Qmax }\left(m^{3} / \mathbf{s}\right) \\
\end{array}$ & $\begin{array}{c}\text { Vazão } \\
\text { Mínima } \\
\text { Qmin }\left(m^{3} / s\right) \\
\end{array}$ & $\begin{array}{l}\text { Coefic.Méd } \\
\text { Variabilid. } \\
\text { Qmax/Qmin } \\
\end{array}$ & $\begin{array}{c}\text { Anos de } \\
\text { maiores picos } \\
\text { de vazão }\end{array}$ \\
\hline $\begin{array}{l}\text { Barra do } \\
\text { Garças }\end{array}$ & 36.423 & 626 & $\begin{array}{c}5.625 \\
(01 / 12 / 2002)\end{array}$ & $\begin{array}{c}101 \\
(27 / 09 / 1972)\end{array}$ & 16 & $\begin{array}{c}2002,2000, \\
1999,1977, \\
1980\end{array}$ \\
\hline Aruanã & 76.964 & 1.175 & $\begin{array}{c}8.374 \\
(17 / 02 / 1980) \\
\end{array}$ & \begin{tabular}{c|c|}
182 \\
$(29 / 09 / 1973)$
\end{tabular} & 13 & $\begin{array}{c}1980,1983, \\
2004,1991, \\
1985\end{array}$ \\
\hline Bandeirantes & 92.638 & 1.447 & \begin{tabular}{c|c|}
5.863 \\
$(20 / 02 / 1980)$
\end{tabular} & $\begin{array}{c}203 \\
(30 / 09 / 1994)\end{array}$ & 12 & $\begin{array}{c}1983,1980, \\
1985,1981, \\
1988\end{array}$ \\
\hline Luis Alves & 117.580 & 1.665 & \begin{tabular}{c|c|}
6.059 \\
$(22 / 02 / 1980)$
\end{tabular} & \begin{tabular}{|c|}
243 \\
$(27 / 09 / 1975)$
\end{tabular} & 10 & $\begin{array}{c}1980,1983, \\
1985,1977, \\
1979\end{array}$ \\
\hline $\begin{array}{l}\text { Fazenda } \\
\text { Telésforo }\end{array}$ & 131.600 & 1.488 & $\begin{array}{c}5.596 \\
(02 / 03 / 1980)\end{array}$ & $\begin{array}{c}182 \\
(08 / 09 / 1971)\end{array}$ & 9 & \\
\hline $\begin{array}{l}\text { São Félix do } \\
\text { Araguaia }\end{array}$ & 193.923 & 2.687 & $\begin{array}{c}9.126 \\
(05 / 03 / 1980)\end{array}$ & \begin{tabular}{c|c}
440 \\
$(10 / 06 / 1973)$
\end{tabular} & 9 & $\begin{array}{c}1980,1997 \\
1979,1977, \\
1978\end{array}$ \\
\hline $\begin{array}{l}\text { Conceição } \\
\text { do Araguaia }\end{array}$ & 320.290 & 5.283 & \begin{tabular}{|c|}
30.143 \\
$(27 / 03 / 1980)$
\end{tabular} & $\begin{array}{c}518 \\
(20 / 09 / 1976)\end{array}$ & 17 & $\begin{array}{c}1980,1979, \\
1978,1997, \\
2002\end{array}$ \\
\hline Xambioá & 364.496 & 5.724 & \begin{tabular}{|c|}
35.760 \\
$(07 / 04 / 1997)$
\end{tabular} & \begin{tabular}{c|c|}
445 \\
$(25 / 09 / 1971)$
\end{tabular} & 18 & $\begin{array}{c}1997,1979, \\
1980,2004, \\
1978\end{array}$ \\
\hline Araguatins & 376.659 & 6.029 & \begin{tabular}{|c|}
26.283 \\
$(20 / 03 / 1979)$
\end{tabular} & \begin{tabular}{|c|}
715 \\
$(05 / 10 / 1975)$
\end{tabular} & 17 & $\begin{array}{c}1979,1980, \\
2004,1978, \\
1985\end{array}$ \\
\hline
\end{tabular}

Distribuição das Vazões dos Principais Afluentes do rio Araguaia

O tamanho da área de drenagem de um sistema fluvial incrementa-se com a entrada dos tributários e em sistemas perenes normalmente se produz um incremento da vazão em direção a jusante. Portanto, é possível relacionar a vazão do sistema principal com a vazão introduzida pelos tributários a medida que se incrementa a rede de drenagem.

No caso do Araguaia as informações hidrológicas dos principais tributários é pouco significativa ou inexistente, pois, há poucas estações hidrológicas nos afluentes e quando existente não representam a totalidade da área de drenagem do tributário por encontrar-se a montante de sua foz. 
Para os tributários de toda a bacia se obtiveram informações de 25 estações hidrológicas através da AnaAgência Nacional de Águas. Porém, muitas dessas estações não se encontram em operação, portanto, neste artigo foram processados dados fluviométricos de 11 estações hidrológicas em operação, embora, muitas delas apresen- tam séries históricas incompletas. A tabela 3 mostra características hidrológicas gerais desses tributários, apresenta valores de vazões médias mensais, máximas mensais e mínimas mensais correspondentes aos aportes de margem direita e esquerda dos tributários que possuem estações hidrológicas.
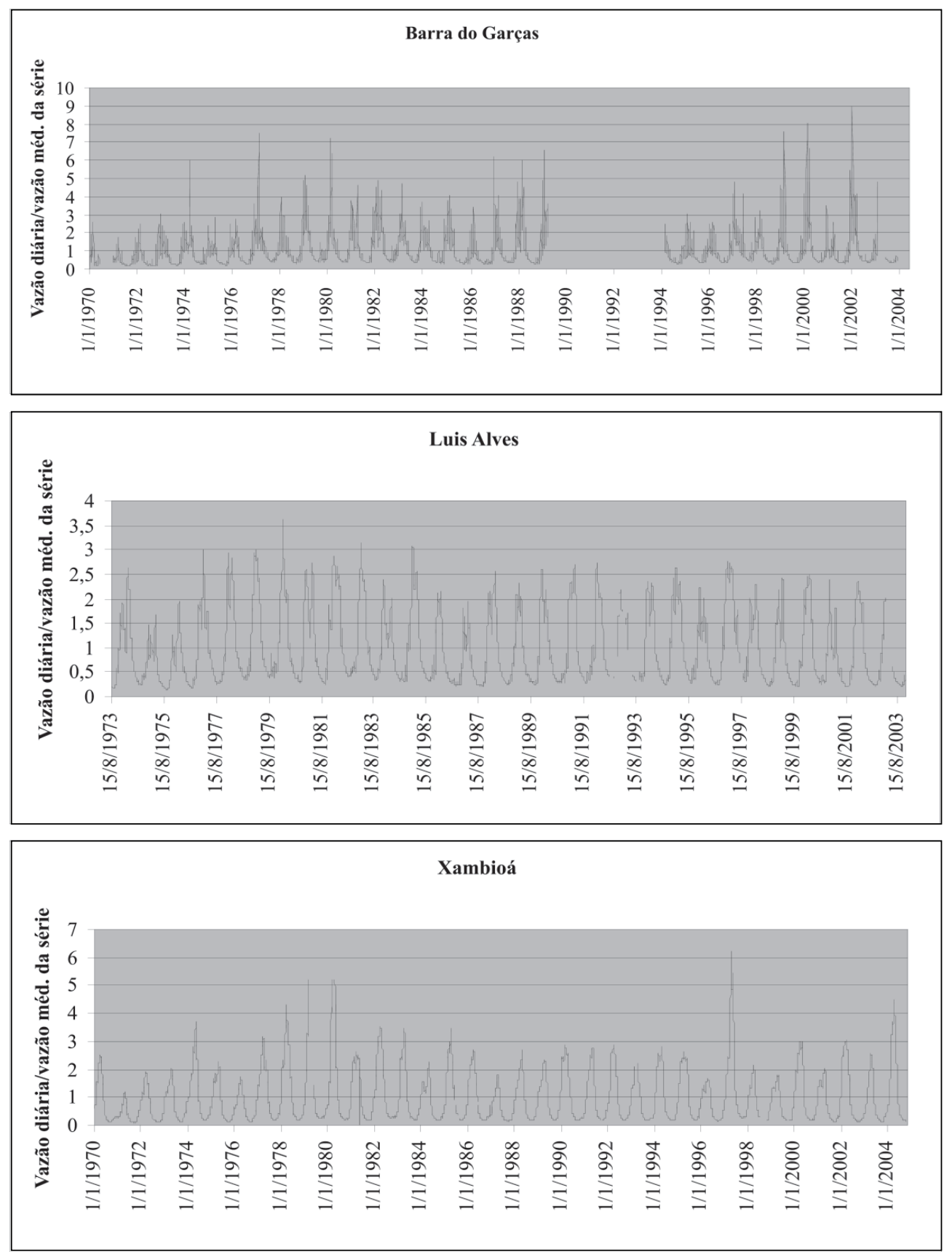

Figura 3 - Hidrogramas de vazão média diária normalizados em relação a média da série histórica de cada estação hidrológica. 
Tabela 3 - Dados hidrológicos referentes às vazões dos tributários do Rio Araguaia que possuem estações fluviométricas.

\begin{tabular}{|c|c|c|c|c|c|c|c|c|}
\hline Rios & Estações & $\begin{array}{c}\text { Série } \\
\text { Histórica }\end{array}$ & $\begin{array}{c}\text { Área } \\
\text { drenagem } \\
\mathbf{k m}^{2}\end{array}$ & $\begin{array}{c}\text { Vazão } \\
\text { média } \\
\text { ms/s }^{3}\end{array}$ & $\begin{array}{c}\text { Vazão } \\
\text { diária } \\
\text { máxima } \\
\text { mºs }^{3} / \mathrm{s}\end{array}$ & $\begin{array}{c}\text { Vazão } \\
\text { média } \\
\text { máxima } \\
\text { m³/s }^{3}\end{array}$ & $\begin{array}{c}\text { Vazão } \\
\text { diária } \\
\text { mínima } \\
\text { ms/s }\end{array}$ & $\begin{array}{c}\text { Vazão } \\
\text { média } \\
\text { mínima } \\
\text { ms }\end{array}$ \\
\hline Mortes & $\begin{array}{c}\text { Sto.Ant. do } \\
\text { Leverger }\end{array}$ & $\begin{array}{c}1969 \mathrm{a} \\
2003\end{array}$ & 59.163 & 899 & $\begin{array}{c}3.462 \\
(02 / 1980)\end{array}$ & 1783 & $\begin{array}{c}196 \\
(09 / 1971)\end{array}$ & 334 \\
\hline Cristalino & \begin{tabular}{|l} 
Jus. Barra \\
Forauilha
\end{tabular} & $\begin{array}{c}1984 a \\
2003\end{array}$ & 8.039 & 104 & $\begin{array}{c}1247 \\
(02 / 1997)\end{array}$ & 351 & $\begin{array}{c}1,59 \\
(10 / 2002) \\
\end{array}$ & 25 \\
\hline Javaés) & $\begin{array}{l}\text { Barr. Do } \\
\text { Pequi }\end{array}$ & $\begin{array}{c}1986 \text { a } \\
1999\end{array}$ & - & 212 & $\begin{array}{c}1210 \\
(03 / 1997)\end{array}$ & 387 & $\begin{array}{c}0,647 \\
(09 / 1999)\end{array}$ & 43 \\
\hline Javaés & $\begin{array}{c}\text { Barr. da } \\
\text { Cruz }\end{array}$ & $\begin{array}{c}1970 \mathrm{a} \\
1999\end{array}$ & 40.320 & 680 & $\begin{array}{c}4.000 \\
(04 / 1982) \\
\end{array}$ & 1682 & $\begin{array}{c}1,78 \\
(09 / 1971) \\
\end{array}$ & 99 \\
\hline Caiapó & $\begin{array}{c}\text { São } \\
\text { Ferreira }\end{array}$ & $\begin{array}{l}1971 \mathrm{a} \\
2003\end{array}$ & 11.804 & 206 & $\begin{array}{c}2574 \\
(02 / 1983)\end{array}$ & 1098 & \begin{tabular}{c|}
16,9 \\
$(09 / 1972)$
\end{tabular} & 41 \\
\hline Claro & $\begin{array}{l}\text { Mtes.Claro } \\
\mathrm{s} \text { de Goiás }\end{array}$ & $\begin{array}{c}1971 \mathrm{a} \\
2003\end{array}$ & 9.765 & 136 & $\begin{array}{c}1.392 \\
(01 / 1977) \\
\end{array}$ & 651 & $\begin{array}{c}10,3 \\
(11 / 2002) \\
\end{array}$ & 26 \\
\hline Vermelho & \begin{tabular}{|l|l} 
Travessão \\
\end{tabular} & $\begin{array}{l}1974 \mathrm{a} \\
2000\end{array}$ & 5.242 & 81 & $\begin{array}{c}1.704 \\
(02 / 1980)\end{array}$ & 593 & $\begin{array}{c}1,4 \\
(08 / 1976)\end{array}$ & 13 \\
\hline $\begin{array}{l}\text { Crixás- } \\
\text { Acu }\end{array}$ & $\begin{array}{l}\text { Jus.Rio } \\
\text { Pintado }\end{array}$ & $\begin{array}{c}1980 \mathrm{a} \\
2003\end{array}$ & 18.600 & 188 & $\begin{array}{c}1.080 \\
(03 / 1977)\end{array}$ & 489 & $\begin{array}{c}3,5 \\
(09 / 2002)\end{array}$ & 38 \\
\hline Formoso & $\begin{array}{l}\text { Proj. Rio } \\
\text { Fomoso }\end{array}$ & $\begin{array}{c}1981 \text { a } \\
1996\end{array}$ & 7.920 & 110 & $\begin{array}{c}399 \\
(01 / 1986)\end{array}$ & 224 & $\begin{array}{c}0,3 \\
(08 / 1984)\end{array}$ & 16 \\
\hline Coco & Caseara & $\begin{array}{c}1999 \text { a } \\
2002\end{array}$ & 5.873 & 118 & $\begin{array}{c}325 \\
(03 / 2002)\end{array}$ & 170 & $\begin{array}{c}1,97 \\
(10 / 1999)\end{array}$ & 72 \\
\hline Piranhas & $\begin{array}{l}\text { Pte.Rio } \\
\text { Piranhas }\end{array}$ & $\begin{array}{c}1981 \mathrm{a} \\
2003\end{array}$ & 1.509 & 26 & $\begin{array}{c}69.2 \\
(02 / 1985)\end{array}$ & 48 & $\begin{array}{c}0,44 \\
(09 / 1990)\end{array}$ & 8,2 \\
\hline Jenipapo & Arapoema & $\begin{array}{c}1988 \text { a } \\
2003\end{array}$ & 1.386 & 28 & $\begin{array}{c}166 \\
(02 / 1993)\end{array}$ & 92 & $\begin{array}{c}1,25 \\
(09 / 1988)\end{array}$ & 7,9 \\
\hline
\end{tabular}

\section{Resultados}

Como acontece no curso principal, o regime hídrico dos tributários está relacionado com as precipitações da região, o período úmido está associado aos meses de novembro a abril, enquanto o período de estiagem corresponde aos meses de maio a outubro. Os máximos picos de cheias se apresentam de janeiro a março, enquanto as mais baixas descargas se apresentam a partir de agosto a novembro, fato associado tanto aos tributários de margem direita como aos que deságuam pela margem esquerda.

Os valores referentes às vazões desses tributários foram relacionados com a regionalização geológica apresenta- da no sub-item 4, que leva em consideração as unidades geológicas na qual está inserida cada afluente, no entanto, apesar de a bacia cortar diferentes unidades não se nota a reação da descarga em função dos relevos e litologias nas quais transcorrem os tributários, sendo a variação de vazão imposta mais pelo clima predominante na bacia.

Porém, é evidente que a grande variabilidade entre picos máximos e mínimos que alguns afluentes apresentam está estabelecida pela ocorrência das estações em zonas de cabeceiras de rápida reação precipitação/ escoamento, por representar uma pequena área de drenagem, e em zonas constituídas por colinas e morros desenvolvidos sobre rochas do embasamento cristalino pré-cambriano ou relacionados a amplas zonas de erosão recuante (ZERS) da bacia do Paraná (Latrubesse e Carvalho, 2006).

\section{Estimativa de Vazão Média Anual para os Tributários do Araguaia}

Embora fossem identificadas 51 sub-bacias a maioria dos tributários não possui estações fluviométricas, não sendo possível analisar seus respectivos regimes hidrológicos.

A análise dos tributários, portanto, somente se concentrou em algumas bacias onde existem dados hidrométricos. Apesar de neste estudo serem considerados os dados existentes de 11 estações fluviométricas, em nenhum caso as estações são representativas da totalidade da área de drenagem da sub-bacia correspondente, devido ao fato de as estações não estarem inseridas na foz do afluente. Portanto, também resulta desconhecido um dado de significativa importância, o aporte líquido dos principais tributários ao sistema coletor do Araguaia.

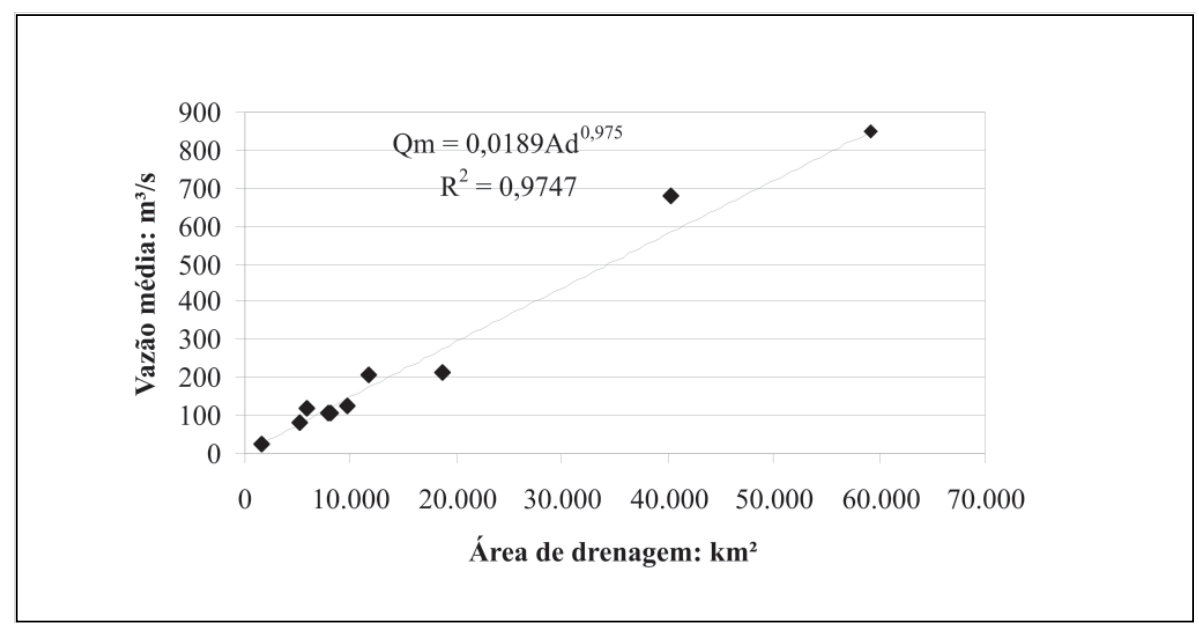

Figura 4 - Área de drenagem x Vazão média anual de 11 tributários do rio Araguaia que possuem estações hidrológicas. 
A partir disso, com o intuito de subsidiar a falta de informações a respeito dos tributários, foi elaborada com os dados existentes de área de drenagem e vazão média dos 11 afluentes que possuem estações hidrológicas, curvas de área de drenagem x vazão, obtendo-se assim, por correlação uma equação de potência de validade regional.

Em termos gerais, os valores de vazões acrescem com o aumento da área de drenagem podendo ser elaborada uma relação, onde a vazão é expressa como uma função da área de drenagem. A obtenção dos gráficos de área de drenagem vs. vazão podem ser de grande utilidade no planejamento ambiental e, especialmente, relacionada para avaliação com os riscos de enchentes (Dunne e Leopold, 1998).

Os dados de vazão média anual das 11 estações (Tabela 3) foram plotados com a área de drenagem correspondente (Figura 4), mostrando uma tendência a aumento de vazão à medida que aumenta a área de drenagem.

A Figura 4 demonstra que a confiabilidade da equação que relaciona a vazão com a área de drenagem é alta $\left(r^{2}=0,9747\right)$. A partir desta equação foi possível estimar com alto índice de confiabilidade a vazão média dos tributários introduzindo na equação a área de drenagem para cada subbacia.

Para o cálculo da área de drenagem foi utilizada a rede de drenagem da bacia do Araguaia disponível em formato digital no SIG Spring e ArcGis, as sub-bacias foram delimitadas e suas respectivas áreas foram obtidas automaticamente.

Com os dados de área de drenagem estimados e utilizando a equação de relação $\mathrm{A}_{\mathrm{d}}$ vs. $\mathrm{Q}$, foram obtidos os valores de vazão média para cada afluente que constitui a bacia principal por meio da equação de correlação: $\mathrm{Q}_{\mathrm{m}}=0,0189 \mathrm{Ad}^{0,975}$

Onde: $Q_{m}=$ vazão média anual $\left(\mathrm{m}^{3} / \mathrm{s}\right) ; \quad A_{d}=$ área de drenagem $\left(\mathrm{km}^{2}\right)$

Os valores de vazões médias anuais estimados para cada sub-bacia encontram-se na tabela 4. E, a representação gráfica da bacia Araguaia com todas as suas sub-bacias identificadas são mostradas na Figura 5.

Tabela 4 - Valores de vazões médias anuais estimadas em função da área de drenagem correspondente a cada tributário.

\begin{tabular}{|c|c|c|}
\hline Margem Direita & A.Drenagem $\left(\mathbf{k m}^{2}\right)$ & Vaz. Média(m $\left(\mathrm{m}^{3} / \mathrm{s}\right)$ \\
\hline \multicolumn{3}{|c|}{ Alto Araguaia } \\
\hline Sist.Princ.e vár.Aflus & 15370.7 & 228.29 \\
\hline Peixes & 5646.8 & 85.99 \\
\hline \multicolumn{3}{|c|}{ Médio Araguaia } \\
\hline Rib. Jurumirin & 983.43 & 25.65 \\
\hline Caiapó & 12697.93 & 189.5 \\
\hline Claro & 11978.93 & 179.03 \\
\hline Vermelho & 14268.84 & 212.32 \\
\hline Javaés & 22960.5 & 337.61 \\
\hline Crixas-Açu & 23682.38 & 347.96 \\
\hline Peixe & 12439.91 & 185.74 \\
\hline 7 & 6333.24 & 96.17 \\
\hline Rib.Sao Domingo & 1124.18 & 27.82 \\
\hline Formoso & 6971.69 & 150.61 \\
\hline 8-A & 5192.46 & 89.24 \\
\hline $8-\mathrm{C}$ & 3421.93 & 62.77 \\
\hline 8-B & 4465.78 & 78.41 \\
\hline 8-D & 4996.13 & 86.32 \\
\hline Coco & 8377.02 & 126.32 \\
\hline Caiapo II & 5334.61 & 91.36 \\
\hline Piranhas II & 6072.69 & 92.31 \\
\hline 12 & 3979.35 & 71.13 \\
\hline 13 & 1857.45 & 39.08 \\
\hline 14 & 1323.38 & 30.9 \\
\hline \multicolumn{3}{|c|}{ Baixo Araguaia } \\
\hline 15 & 3277.08 & 50.59 \\
\hline Jenipapo & 1837.17 & 28.77 \\
\hline Muricizal & 3405.44 & 52.52 \\
\hline Lontra & 4415.14 & 67.65 \\
\hline 18 & 3587 & 55.25 \\
\hline Corda & 4596.55 & 70.36 \\
\hline Piranhas III & 1937.94 & 30.31 \\
\hline Martinho & 1395.88 & 22.01 \\
\hline Barreiro & 704.03 & 11.29 \\
\hline Total & $204,635.56$ & $3,223.28$ \\
\hline
\end{tabular}

\begin{tabular}{|c|c|c|}
\hline Margem Esquerda & A.Drenagem $\left(\mathbf{k m}^{2}\right)$ & Vaz. Média(m³/s) \\
\hline \multicolumn{3}{|c|}{ Alto Araguaia } \\
\hline Garças & 13778.09 & 250.2 \\
\hline Diamantino & 3892.48 & 60.54 \\
\hline \multicolumn{3}{|c|}{ Médio Araguaia } \\
\hline das Mortes & 59792.94 & 858.41 \\
\hline Cristalino & 13383.42 & 199.46 \\
\hline Varios Afluentes & 4695.6 & 81.84 \\
\hline III & 7114.76 & 170.73 \\
\hline Tapirapê & 16522.77 & 244.96 \\
\hline $\mathrm{V}$ & 666.45 & 10.71 \\
\hline VI & 4918.76 & 75.17 \\
\hline VII & 2327.33 & 36.24 \\
\hline VIII e IX & 5531.63 & 84.28 \\
\hline $\mathrm{X}$ & 6424.7 & 97.53 \\
\hline XI. XII. XIII e XIV & 11116.75 & 166.45 \\
\hline XV e XVI & 7450.89 & 112.68 \\
\hline \multicolumn{3}{|c|}{ Baixo Araguaia } \\
\hline Pau d'Arco & 7719.5 & 116.64 \\
\hline Rib. Das Andorinhas & 4872.6 & 74.48 \\
\hline Rib.Agua Fria & 2527.94 & 39.28 \\
\hline Itaipava & 547.12 & 8.83 \\
\hline Xambioa e peq.afluentes & 3953.5 & 63.51 \\
\hline Gameleira e peq.afluentes & 2126.65 & 33.19 \\
\hline Total & $179,363.88$ & $2,785,13$ \\
\hline
\end{tabular}




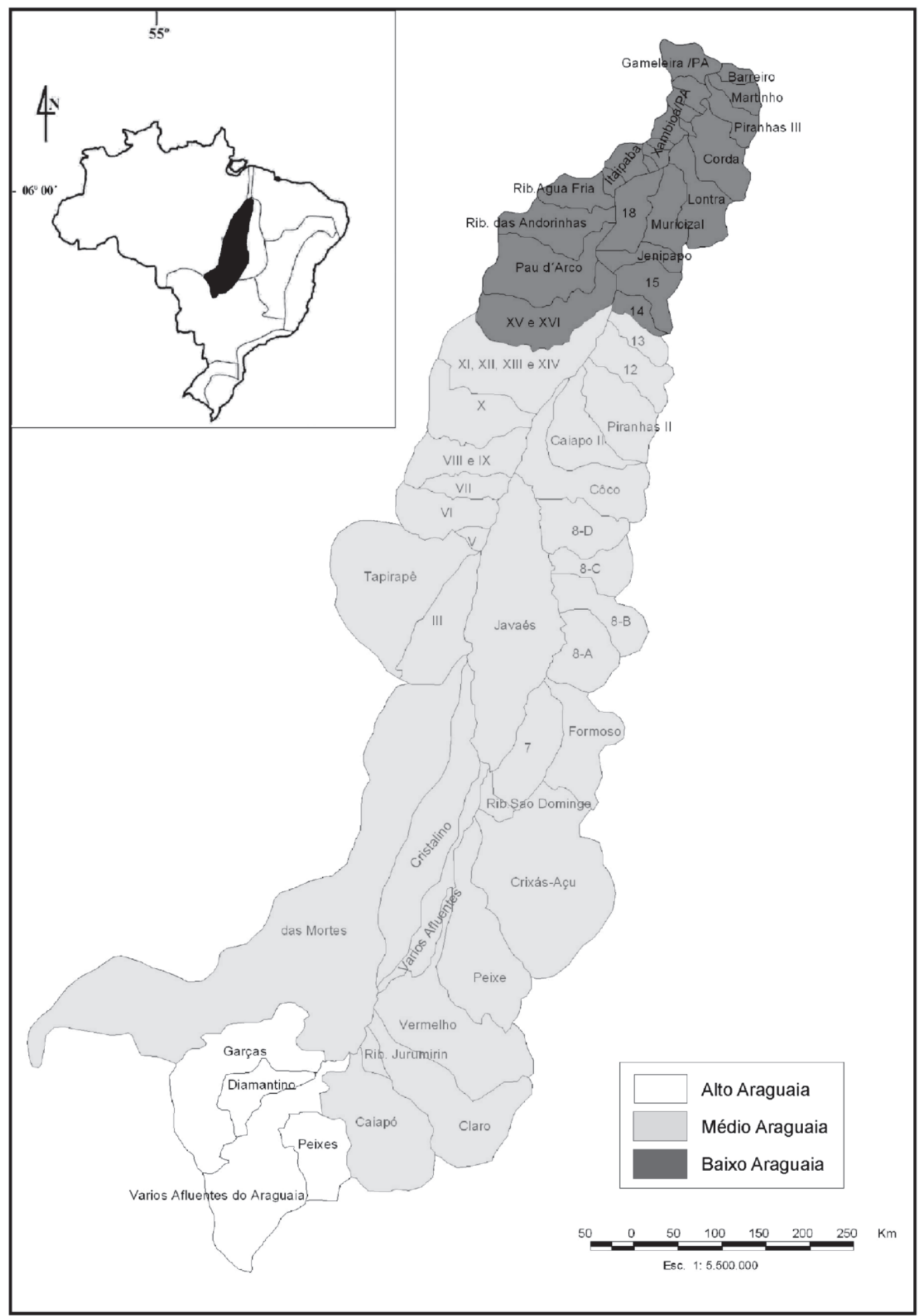

Figura 5 - Área de drenagem das sub-bacias do Araguaia

No caso das denominadas sub-bacias Xambioá e pequenos afluentes, as quais englobam diversas bacias menores, o valor representa a somatória de todos os valores obtidos para cada bacia individualmente.
Através desses cálculos encontraram-se resultados de que os aportes na alta bacia são mais significativos pela margem esquerda, mas em total representam a ordem de aproximadamente $625 \mathrm{~m}^{3} / \mathrm{s}$, o qual representa $10,4 \%$ do fluxo da 
bacia, enquanto, no médio curso a incidência dos afluentes é muito mais significativa, correspondendo a uma descarga de $4.658,71 \mathrm{~m}^{3} / \mathrm{s}$, contribuindo com $77,54 \%$ da descarga total. Já o baixo curso aporta vazão média de $724,68 \mathrm{~m} 3 / \mathrm{s}$, constituindo-se em $12,06 \%$ do valor total da descarga.
A Figura 6 mostra as somatórias da entrada dos tributários por margem direita e esquerda no alto, médio e baixo Araguaia, com seus respectivos valores estimados de vazão média anual.

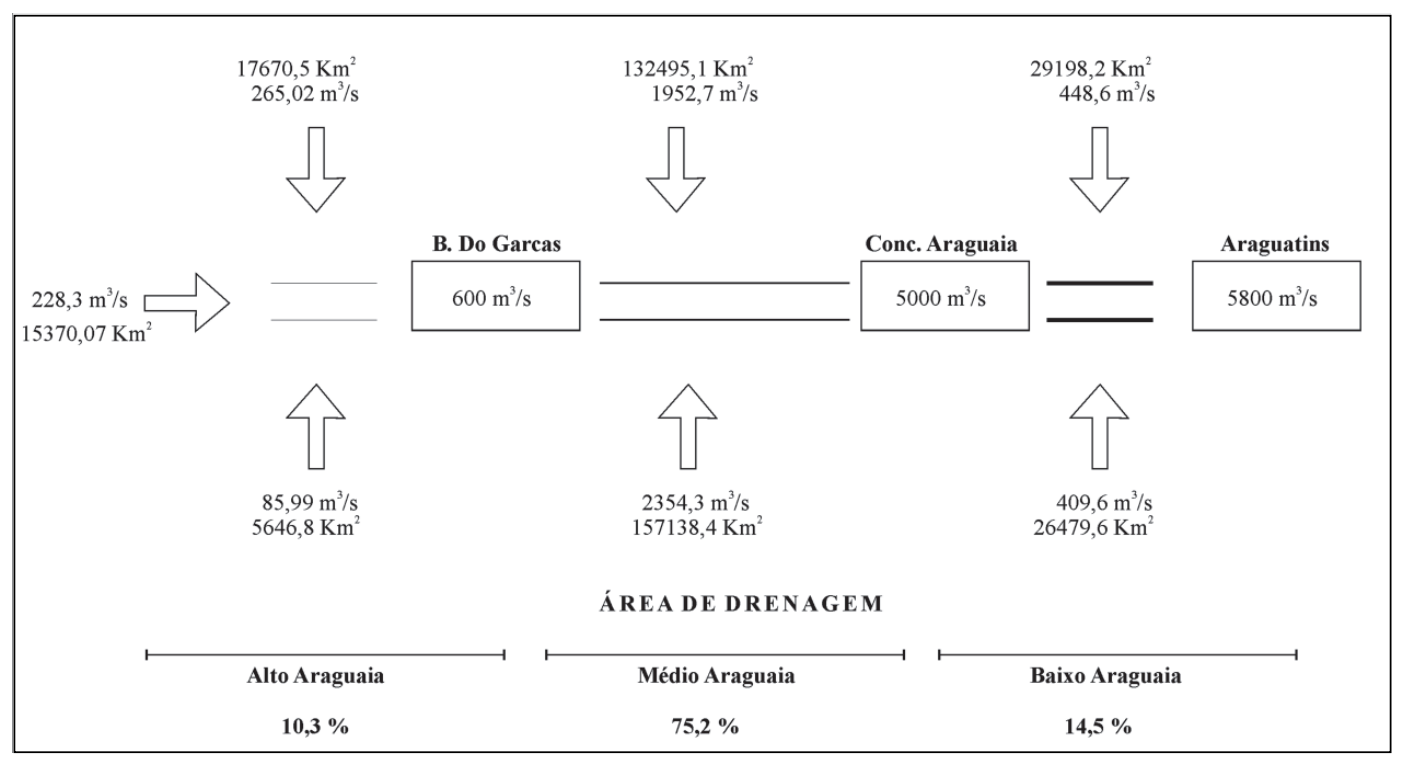

Figura 6 - Aportes de vazão média das margens esquerda e direita no Alto, Médio e Baixo setor, e quanto contribuem, em porcentagem, na bacia do rio Araguaia.

Os principais afluentes do médio rio Araguaia são predominantemente de sua margem direita, ou seja, pertencem ao Estado de Goiás, constituindo-se em 19 bacias, enquanto, os que entram por margem esquerda se distribuem em 11 bacias. Adicionalmente, no curso médio, 7 bacias não entram de forma direta no rio Araguaia, são sub-tributários do rio Javaés.

Através da margem esquerda, o Araguaia recebe a bacia do rio das Mortes que representa 33\% do total de entrada nesta margem, em área de drenagem e 14,29\% em vazão de toda a bacia.

\section{Considerações Finais}

Embora os afluentes do Araguaia drenem uma variada diversidade de ambientes geológicos e geomorfológicos a análise do comportamento hidrológico de 11 tributários que possuem estações hidrológicas tem apresentado, em forma geral, um comportamento hidrológico similar, altamente dependente do clima regional.

Os dados hidrológicos serviram de base para o processamento e análise de uma curva de validade regional área de drenagem $x$ vazão que permitiu a obtenção de dados até hoje desconhecidos e de significativa importância para o planejamento de recursos hídricos e manejo de bacias: os aportes líquidos médios anuais de cada tributário na bacia do Araguaia.

A respeito da entrada por margens, a totalidade dos afluentes da margem esquerda contribuem com 179.363,88 $\mathrm{km}^{2}$ de área de drenagem e $2.785,13 \mathrm{~m}^{3} / \mathrm{s}$ de vazão média anual, enquanto os da margem direita aportam $3.223,28 \mathrm{~m}^{3} / \mathrm{s}$ drenando uma totalidade de 204.635,56 $\mathrm{km}^{2}$.

No médio curso, os tributários que entram por margem direita equivalem a $158.461,83 \mathrm{~km}^{2}$ de área de drenagem e $2.520,25 \mathrm{~m}^{3} / \mathrm{s}$ de vazão média anual, e os que entram por margem esquerda representam $139.946 \mathrm{~km}^{2}$ e $2.138,46 \mathrm{~m}^{3} / \mathrm{s}$ de vazão média anual.

O baixo curso é constituído por sub-bacias menores que as do setor de médio curso e representam $25.156,23 \mathrm{~km}^{2}$ e $388,75 \mathrm{~m}^{3} / \mathrm{s}$ por margem direita, e $21.747,31 \mathrm{~km}^{2}$, com $335,93 \mathrm{~m}^{3} / \mathrm{s}$ de vazão média anual por margem esquerda.

O erro indica um defeito de vazão da ordem de aproximadamente $5 \%$. Tendo em conta a alta probabilidade da curva, é possivel que parte dos erros sejam próprios da determinação da área de drenagem, mas também, possivelmente é devido aos aportes sub-superficiais de recarga da planície aluvial e talvez alguma pequena contribuição da Planície do Bananal ao sistema fluvial. 


\section{Agradecimentos}

Ao CNPq, pela concessão da bolsa de estudos, ao Nupelia/UEM, ao Labogef/UFG e a Agência Nacional de Águas, pelo fornecimento de dados hidrológicos. Este trabalho é uma contribuição da Rede CABAH XII K CYTED/ CNPq e Projeto: Land Use Impacts on the Water Resources of the Cerrado Biome subsidiado por NASA/LULCC.

\section{Referências Bibliográficas}

AGMA, AGETOP, WWF e IMAGEM. 2004. PDIAP - Projeto de Identificação de

Áreas Prioritárias para a Conservação da Biodiversidade no Estado de Goiás. Goiânia: AGMA. [Formato digital].

Arruda, M., Dias, A. Latrubesse, E.M. Galinki, M. 2000. Projeto Corredor Ecológico

Bananal/Araguaia. Ibama: Publicação especial. 120 p.

BRASIL. Ministério do Meio Ambiente. Primeiro relatório nacional para a convenção

sobre diversidade biológica - Brasil. Serviços do ponto focal brasileiro do mecanismo de informação da convenção sobre diversidade biológica. Disponível em: http://www.mma.gov.br/port/sbf/chm/ relato.html. Acesso em: 03 de abril 2003.
Dunne T. Leopold, L.B. 1998. Water and environmental planning. W.H.Freeman and Company, New York. 818p.

Latrubesse, E. e Carvalho, T.M. 2006. Geomorfología do Estado de Goiás. Superintendencia de Geología e Mineracão do Estado de Goiás, 143p, Goiânia, Brasil.

Latrubesse, E.; Stevaux, J.C. e Sinha, R. Tropical Rivers. Geomorphology, 70, 187-206, 2005.

Latrubesse, E. e Stevaux, J. C. 2002. Geomorphology and Environmental Aspects

of Araguaia Fluvial Basin, Brazil. In: Z. Geomorphologie. Berlim: Suppl.-Bd. 129,. 109-127.

Marinho, G.V. Castro,S. S. e Campos, A. B. 2006. Hydrology and gully processes in the upper Araguaia River Basin, Central Brazil, Zeitschrift fur Geomorphologie 145,119-145.

SGM - Superintendência de Geologia e Mineração do Estado de Goiás. 2006. Caracterização Climática do Estado de Goiás. Por: Silva S.C., Santana N.M.P. e Pelegrini J.C. Secretaria de Industria e Comércio.

Souza, I. F. 2002. Compartimentação da rede de drenagem da Bacia Hidrográfica do rio Araguaia. Monografia (Curso de Especialização em Geografia) Instituto de Estudos Sócio-Ambientais, Universidade Federal de Goiás, Goiânia, GO. 110p. 